\title{
Pitting Growth Rate in Carbon Steel Exposed to Simulated Radioactive Waste \\ (U)
}

by

P. E. Zapp

Westinghouse Savannah River Company

Savannah River Site

Aiken, South Carolina 29808

A document prepared for CORROSION/96 at Denver from 03/24/96 - 03/29/96.

DOE Contract No. DE-AC09-89SR18035

This paper was prepared in connection with work done under the above contract number with the U.S.

Department of Energy. By acceptance of this paper, the publisher and/or recipient acknowledges the U.S. Government's right to retain a nonexclusive, royalty-free license in and to any copyright covering this paper, along with the right to reproduce and to authorize others to reproduce all or part of the copyrighted paper.

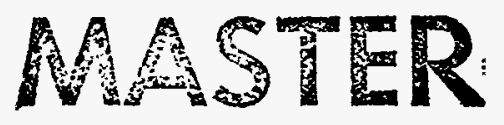




\section{DISCLAIMER}

This report was prepared as an account of work sponsored by an agency of the United States Government. Neither the United States Government nor any agency thereof, nor any of their employees, makes any warranty, express or implied, or assumes any legal liability or responsibility for the accuracy. completeness, or usefulness of any information, apparatus, product, or process disclosed, or represents that its use would not infringe privately owned rights. Reference herein to any specific commercial product, process, or service by trade name, trademark, manufacturer, or otherwise does not necessarily constitute or imply its endorsement, recommendation, or favoring by the United States Government or any agency thereof. The views and opinions of authors expressed herein do not necessarily state or reflect those of the United States Govemment or any agency thereof.

This report has been reproduced directly from the best available copy.

Available to DOE and DOE contractors from the Office of Scientific and Technical Information, P. O. Box 62, Oak Ridge, TN 37831; prices available from (615) $576-8401$.

Available to the public from the National Technical Information Service. U. S. Deparment of Commerce, 5285 Port Royal Rd., Springfield. VA 22161 


\title{
PITTING GROWTH RATE IN CARBON STEEL EXPOSED TO SIMULATED RADIOACTIVE WASTE
}

\author{
Philip E. Zapp \\ Savannah River Technology Center \\ Westinghouse Savannah River Co. \\ Aiken SC 29808
}

\begin{abstract}
Dilute high-level radioactive waste slurries can induce pitting corrosion in carbon steel tanks in which such waste is stored and processed. The waste is normally maintained with closely monitored nitrite and hydroxide concentrations known to prevent the initiation of pitting. Coupon immersion are being conducted in laboratory simulants of waste to determine the probability and growth rate of pitting in steel in the event of below-limits nitrite concentrations. Sets of about 36 carbon steel coupons have been immersed in known corrosive conditions (nitrite $<5 \%$ of the established limit) at a temperature of $50^{\circ} \mathrm{C}$. Three sets have been removed from testing after 64, 150, and 350 days of immersion. The long immersion times introduced variability in the exposure conditions due to the evaporation and replenishment of solution. The deepest corrosive attack was measured on each coupon by optical microscopy. The deepest pits were ranked and analyzed as a type 1 extreme value distribution to extrapolate from the coupon population to the maximum pit depths in a waste tank structure. The data were compared to a power law for pit growth, although the deepest pits did not increase monotonically with time in the limited data set.
\end{abstract}

Keywords: Localized corrosion, extreme value statistics, coupon immersion, nitrite, inhibitor

\section{INTRODUCTION}

Localized corrosion is a broad term that describes the forms of corrosion in which the attack is not evenly distributed over a surface. Localized corrosion has been defined to include such distinct forms as pitting, crevice corrosion, intergranular corrosion, stress corrosion cracking, corrosion fatigue, cavitation attack, and others. ${ }^{1}$ Some investigators have defined the term more narrowly. Uhlig identifies localized corrosion as either pitting or crevice corrosion, ${ }^{2}$ and this definition generally prevailed at a recent conference on advances in the understanding of localized corrosion. 3 The industrial impact of localized corrosion is significant. Based on the inclusive definition, an analysis of metallic failures at one American chemical plant revealed that localized corrosion mechanisms were responsible for about two thirds of the failures, while general corrosion 
was responsible for fewer than one fourth. ${ }^{4}$ A large fraction of the localized corrosion failures occurred by pitting.

The definition of pitting rests upon the concept of passivity in metals. Pitting is the local electrochemical dissolution of metal from a surface that is electrochemically passive. Passivity arises from the growth of a stable, non-porous oxide film that markedly impedes the rate of general dissolution of the alloy in reactive environments. Pitting is inherent in the performance of engineering alloys, such as iron- and aluminumbased alloys, because these alloys derive their utility and stability in potentially corrosive environments from the presence of a passive oxide film on their exposed surfaces. Pitting may begin with a small, randomly located breach of the passive film, which exposes the underlying alloy to the environment and active corrosion. The anodic reactions in the initiated pit can occur at a very high rate because the supporting cathodic reactions take place on the large remaining passive surface. Most of the surface undergoing pitting continues to be passive. The ratio of pitting current density to passive surface current density may be as high as $10^{6.5}$

Pitting is perhaps the most difficult corrosion form to evaluate and characterize in an engineering structure or component, because of the randomness of its initiation and propagation. Ives has defined five stages in the development of a corrosion pit: (1) local breakdown of the passive film, (2) high anodic dissolution current density, (3) competition between repassivation and establishment of continuing pit growth, (4) growth from atomic scale to microscopic scale, and (5) growth from microscopic to macroscopic size, or simply, macroscopic pitting. 6 The literature on pitting is extensive and largely focussed on its early stages. ${ }^{7}$ From the point of view of engineering service of materials, macroscopic pitting is of greatest interest. It is typically the through-thickness macroscopic pit that results in the failure of a structure. However, stage (5) pit growth is far less studied than the earlier stages. This is probably due to the random nature of the growth, growth rate, and cessation of growth and the cost and technical challenges in the study of macroscopic pitting. As will be discussed below, the successful approach to understanding macroscopic pit growth is based statistically on measurements of large populations of pits.

\section{Prevention of Pitting in High-Level Radioactive Waste Solutions}

High-level radioactive waste at the United States Department of Energy's Savannah River Site (SRS) is stored in large carbon steel tanks. In 1996 the Department will begin immobilizing this waste in a borosilicate glass waste form for permanent disposition. The process for vitrifying the high-level radioactive waste requires that the waste slurries be washed to remove soluble salts. Washing will be conducted in existing carbon steel tanks similar to those in which the waste is stored. Washing lowers the concentration of hydroxide, which in stored waste is maintained at a concentration sufficient to prevent pitting and stress corrosion cracking. Near the liquid waste/vapor interface and in an aqueous film on the tank wall above the interface, the hydroxide concentration is decreased below its bulk value by reaction with absorbed atmospheric carbon dioxide. This reaction proceeds rapidly, and the diffusion of hydroxide from the bulk liquid to the film is slow enough to result in a steady-state hydroxide concentration in the film that is 3 to 4 orders of magnitude lower than the bulk concentration. The tank wall and the pipes of the tank cooling system at the liquid-vapor interface are the areas most vulnerable to pitting. Hydroxide is also destroyed by radiolysis and consumed through reaction with organic acids in certain waste streams. Over a few years, the hydroxide concentration of the entire volume of washed waste slurry would decline to the low steady-value without replenishment, and the waste would become corrosive to the steel. Thus, through dilution and chemical reaction, the hydroxide concentration in washed waste slurries is insufficient to prevent pitting corrosion.

The technical approach to the control of pitting corrosion has been to modify the waste chemistry to prevent the initiation of pitting. Prevention of initiation was deemed a tractable technical problem, while the control of pitting by retarding its propagation was thought to be too complex. Extensive laboratory studies, using electrochemical and coupon immersion test methods, have been conducted to identify a corrosion inhibitor that will supplement the remaining hydroxide to prevent pitting. Through these studies, nitrite was 
shown to be an effective inhibitor and the concentrations of nitrite necessary to prevent the initiation of pitting in dilute waste slurries were determined. 8,9 Various nitrite levels were tested throughout the range of possible waste compositions and temperatures. Nitrite was shown to depend upon the temperature and a single aggressive anion concentration. The principal aggressive anion is generally nitrate. Where the nitrate concentration is reduced by radiolysis to a sufficiently low value, sulfate or chloride may induce pitting in carbon steel and control the required nitrite level. ${ }^{8}$ Equations relating the safe nitrite level to the waste temperature and its nitrate, sulfate, or chloride concentration are incorporated into the process requirements for the vitrification feed preparation tanks.

The process requirement nitrite equations are conservative. They incorporate a $50 \%$ safety factor over the equations fitted to the experimental data, and the experimental data were conservatively measured. This conservatism has been scrutinized because of an undesirable downstream effects of nitrite in the vitrification feeds. These effects have resulted in the construction of a new stainless steel facility in which nitrite can be washed out of one of the feeds. The present study was undertaken partly in response to the need to understand the extent of the pitting problem as it impacted the conservative nitrite inhibitor concentrations. The approach of the present work has been to determine the pitting response in an intentionally corrosive dilute waste solution.

\section{Macroscopic Pit Growth in Carbon Steel}

The kinetics of pit growth are widely described with a power law of the form

(1)

$$
P=k t^{n}
$$

where $P$ is pit depth, $t$ is time, $k$ is a constant dependent upon material and environment, and $n$ is a numerical constant. 7 This form was proposed to describe the pits measured on numerous ferrous materials in the very large National Bureau of Standards underground corrosion program that was conducted from 1922 to 1952. The program was summarized in the frequently cited monograph by Romanoff. 10 The exponent $n$ was usually in the range 0.5 to 0.6 , but varied widely from near zero to 0.92 . The constant $k$ varied from 20 to 107 . Equation 1 is not predictive in a quantitative sense in the NBS underground corrosion survey, which is perhaps expected given the wide range of environments in which the data were acquired. Nonetheless a review of the NBS data along with other long-term corrosion databases concludes that Equation 1 fits the data as well or better than other formulas. 11 In other applications of Equation 1 the value of $\mathrm{n}$ was determined to be 0.33 in aluminum and 0.5 in mild steel. ${ }^{6}$ It varied from 0.3 to 0.7 in alloy 600 in a temperature dependent manner. ${ }^{12}$ More recent work on a mild steel developed the following area-adjusted equation for the maximum pit depth on a radioactive waste canister

$$
P=8.35 t^{0.46}
$$

where depth $\mathrm{P}$ is in millimeters and $\mathrm{t}$ is the time in years. The steel was immersed in slightly alkaline (pH 8.4) synthetic granitic ground water at $90^{\circ} \mathrm{C}$, and the corrosive agent was chloride. ${ }^{13}$ The growth of pits in a low alloy steel exposed to deionized water at $65^{\circ} \mathrm{C}$ resulted in a power law of

$$
P=13.65 t^{0.584}
$$

where $P$ is in micrometers and $t$ in hours.

The NBS studies investigated the relationship between the size of the specimen or structure under study 
with the depth of deepest pits or corrosive attack. It was concluded from the NBS observations that the depth of the deepest pits $P_{d}$ increases with increasing specimen area $A$ according to

(4)

$$
P_{d}=b A^{m}
$$

or

$$
P_{d}=c+d \ln A
$$

(5)

where $b, c, d$, and $m$ are constants. Equations 4 and 5 represent the observations that the larger the specimen, the deeper is the pit likely to be measured.

\section{Extreme Value Theory}

As stated above, in many cases the few deepest pits are of much greater interest than the many shallower pits. If pitting is random and there is a statistical distribution of pit depths, then the deepest pits themselves conform to a statistical distribution. It usually is not possible to determine the underlying distribution of all pit depths because the smallest cannot be readily measured. However the statistics of extreme values have been found useful in analyzing and characterizing the distribution of deepest pits. The development of extreme value theory for engineering applications is credited throughout the corrosion literature to Gumbel. In particular, extreme value theory has provided the mathematics to predict the deepest corrosive attack in a large structure from a limited number of measurements on a portion of the structure, or alternatively, the deepest corrosive attack on a large number of coupons from measurements on only a fraction of that number. Gumbel's work was first applied to pitting corrosion by Aziz, who used the theory to analyze pit depths on aluminum coupons and pipes exposed to potable and sea water ${ }^{14}$ and by Eldredge, who analyzed pits in oil well tubing. 15 There were subsequent applications of extreme value theory to pitting on steel pipelines. 16 Interest in the long-term performance of radioactive waste containers stimulated more recent use of extreme value theory, and the National Institute of Standards and Technology (formerly the National Bureau of Standards) has sponsored work in the field recently.

In connection with radioactive waste storage, $\mathrm{McNeil}$ has reviewed some statistical issues associated with carbon steel pitting. 17 He considered especially how extreme value theory may properly be applied to pitting data. There are three types of distribution cited in the corrosion literature: type 1, the exponential type; type 2, the Cauchy type; and type 3, the limited type. These may be differentiated by the bounds placed on allowed measurements. In type 1 distributions, there are no bounds to the data, whereas in type 2 and type 3 distributions the measured data are bounded by a minimum and a maximum allowed value, respectively.

Mathematically, the type 1 distribution is the simplest, having an exponentially decreasing probability of occurrence with increasing value of the variate. Many common distributions, such as the exponential and normal distributions, converge asymptotically at extreme values to the type 1 distribution. Its form is the double exponential

(6)

$$
F(x)=e^{-e^{-y}}
$$

with the reduced variate $y$ given by

$$
y=\alpha(x-u)
$$


where $y$ lies in the range $-\infty<y<\infty, u$ is a parameter defining the location of the distribution, and $a$ a parameter defining the scale (or width) of the distribution. $F(x)$ is interpreted as the probability that there are no observations (e.g., pit depths) deeper than $x$. The quantity $1-F(x)$ is the probability of measuring a pit deeper than $x$, or, alternatively, the risk of accepting $x$ as the deepest possible pit. The reciprocal of 1 $F(x)$ is called the "return period."

As stated above, the early use of extreme value theory in pitting analyses is credited to Aziz and Eldredge. They interpreted their data with the exponential type 1 distribution. The unbounded range of this distribution is somewhat unphysical in the field of corrosion because it does not reflect the finiteness of the corroding structure or the electrochemical limits to pitting that are enforced by the IR drop through an increasing long electrolyte circuit path. Nonetheless the type 1 distribution has been acknowledged to yield satisfactory results.

\section{EXPERIMENTAL}

Coupon immersion tests were conducted with ASTM A.537 Class 1 carbon steel coupons in a nonradioactive simulant of a dilute sludge slurry. The simulant composition is shown in Table 1. Two 36-liter volumes of solution were mixed from reagent-grade chemicals and distilled water. The solutions were adjusted to a $\mathrm{pH}$ of 9.73 with sodium hydroxide. The total nitrate concentration was $0.0546 \mathrm{M}$, with the nitrate ion contributed mainly by sodium nitrate, aluminum nitrate, and ferric nitrate. The corrosion database indicates that, for this nitrate level, the minimum nitrite concentration required to prevent pitting is 0.16 at the planned immersion temperature of $50^{\circ} \mathrm{C}^{8}$ The actual nitrite concentration in the simulant was $0.005 \mathrm{M}$ to ensure that the solution would induce pitting.

The coupons used in this study were fabricated from ASTM A537 class 1 carbon steel and supplied by Metal Samples, Inc., Munford, Ala. Their size was $6.0 \mathrm{in}$. by $2.0 \mathrm{in}$. by 0.12 in., and they were used in the asreceived condition with 600 grit surface finish. Two coupons were placed in 1-L plastic bottles, which were filled with test solution to a mark to cover the coupons. The entire test consisted of 70 bottles containing 140 coupons. The bottles uere placed in convection ovens maintained at $50 \pm 2^{\circ} \mathrm{C}$. Sets of coupons were scheduled for periodic removal. Some evaporation occurred, leading to the exposure of some coupons to a liquid/vapor interface. The bottom of the coupons rested in settled solids (ferric hydroxide, manganese dioxide) which, along with the coupon contact with the bottle bottom, created a crevice effect. In some instance the one coupon rested against the other, which created a large crevice. As will be noted below, the interface and crevice regions on some coupons were the sites of deep corrosive attack.

Upon removal from the test, the coupons were cleaned of corrosion products in either an inhibited hydrochloric acid solution or in a sodium hydroxide solution/zinc mixture, according to ASTM standard practice. Considerable corrosion product remained and was removed mechanically from pits with either a sharp steel stylus or a carbide-tipped vibratory engraving tool. The coupons were then examined with optical microscopy, and depth of corrosion attack was measured with a calibrated focus microscope. The standard practice for pit depth measurement was first to focus the microscope uncorroded metal near the location of interest and then zero the digital readout of the dial micrometer attached to the microscope stage. The bottom of the feature was then brought into focus and the depth read from the readout. The smallest division on the readout was $0.1 \mathrm{mil}(2.5 \mu \mathrm{m})$ The uncertainty in the point of sharp focus for the bottom resulted in an uncertainty in the measurement of about \pm 0.3 mils $(8 \mu \mathrm{m})$. Selected coupons were also sectioned to measure pit depths by serial metallography.

\section{RESULTS}

The present results consist of maximum pit depths from three sets of coupons that were immersed for 64 , 
150, and 350 days, respectively. As expected, the test solution produced significant corrosion. Most coupons had patches of what has been termed uneven local corrosion, 18 with otherwise unattacked metal between the patches. Few coupons had isolated small pits only. This corrosion was located generally (1) at the liquid/vapor interface near the top of the coupon, (2) down the length of the coupon in roughly vertical trailing bands, and (3) at the coupon bottom in contact with the bottle or with solids. The vertically trailing corrosion has been frequently noted as evidence of the ability of corrosion products to induce further corrosion as gravity draws them down to fresh metal surface. 18 The corrosion products were primarily magnetite with some goethite as revealed by $x$-ray diffraction.

Within the patches of uneven local corrosion, there was aggressive attack that produced pits markedly deeper than the adjacent corrosion. A wire brush, steel scribe, vibratory engraver were used to dislodge the rust that remained after chemical cleaning. Very little underlying uncorroded steel was disturbed. This procedure was followed on both front and rear faces of the coupon. With the rust removed, the coupons were examined with a binocular microscope at magnifications up to $68 \mathrm{X}$ to identify deepest pits for measurement at magnifications up to $400 \mathrm{X}$. Pits that were near, and influenced by, an edge of a coupon were not included in the measurements. The results of the deepest pit measurements are shown in Tables 2 . The measurements ranged from $1.0 \mathrm{mil}(25 \mu \mathrm{m})$ to $31.3 \mathrm{mil}(800 \mu \mathrm{m})$ in the 64-day data set, from $1.0 \mathrm{mil}(25 \mu \mathrm{m})$ to $49.4 \mathrm{mil}(1.250$ $\mu \mathrm{m})$ in the 150 -day set, and from $8.7 \mathrm{mil}(220 \mu \mathrm{m})$ to only $34.3 \mathrm{mil}(870 \mu \mathrm{m})$ in the 350 -day set. The data are shown in Table 2, where the coupons are identified by number and ranked in order of increasing depth of the deepest pit.

It is interesting to contrast these measurements with those of Marsh et al., which were made on mild steel in slightly alkaline synthetic ground water at $90^{\circ} \mathrm{C}$. Those measurements ranged from about 80 mils (2000 $\mu \mathrm{m})$ to 320 mils $(8000 \mu \mathrm{m})$ in the time period 40 days to 400 days. ${ }^{13}$ The electrolyte was similar to that of the present work. The greater corrosive attack is consistent with greater test temperature.

The depths have been analyzed as a type 1 extreme value distribution. The procedure of Aziz was used to assign a plotting position on the ordinate for the relevant measured depth on the abscissa. This position is the cumulative frequency of the distribution and is obtained by dividing the rank of the measurement, $m$, by the sum of 1 plus the total number of coupons $N$. The cumulative frequency can be converted to the linear scale of the reduced variate $y$ of Equation 5 by a double logarithmic transformation

$$
y=-\ln \left[-\ln \left(\frac{m}{N+1}\right)\right]
$$

This converted cumulative frequency has been plotted against the mth pit depth in Figures $1 \mathrm{~A}$ least squares fitting routine in Microsoft Excel ${ }^{\mathrm{TM}}$ software was used to fit linear equations to the data. The results of the fits to each immersion period are shown in Table 3 , along with the appropriate $R^{2}$ coefficient. The latter are clustered about 0.9 .

The linear equations can be usefully extrapolated to investigate the likelihood of a deepest pit on larger surface areas. This procedure uses the concept of the return period. In practical terms, the return period, $T$, is "the number of coupons that must on average be exposed in order to obtain a pit depth greater than the observed pit depth."14 In the present work, we are interested in applying the coupon results to a large carbon steel waste tank. Thus, the return period is the area of the waste tank that is vulnerable to pitting corrosion relative to the area of the coupon exposed in the experiment. In the analysis the entire area of the coupon is considered.

The area of a coupon was $24.0 \mathrm{in.}\left(0.0155 \mathrm{~m}^{2}\right)$. The area of primary tank wall of an $85-\mathrm{ft}(26-\mathrm{m})$ diameter waste tank (0.50-in. [12-mm] wall thickness) that is subject to corrosive conditions of washed sludge slurry is 19200 in. $^{2}\left(12.4 \mathrm{~m}^{2}\right)$, based on an aqueous film extending $6 \mathrm{in.}(0.015 \mathrm{~m})$ above the liquid/vapor interface. 
Dividing the coupon area into the waste tank area yields a value of 800 for the return period T. The expected deepest pits are said to converge to

$$
x=\mu+\frac{\ln T}{\alpha}
$$

for type 1 extreme value distributions. ${ }^{14}$ Inserting the values for $\mathrm{T}$ and the distribution parameters yields the expected deepest pits for the experimental periods. These are listed at the bottom of Table 3 . The deepest pit expected to develop in a tank in a 64 -day period of aggressive conditions is 36 mils $(910 \mu \mathrm{m})$; in a 150-day period the pit is expected to be 50 mils $(1300 \mu \mathrm{m})$ and in 350 days, 30 mils $(760 \mu \mathrm{m})$.

Although the minimum deepest pit is largest for the longest immersion, the maximum deepest pit measured was not in the 350-day data set but rather in the 150-day set, and, thus, the deepest pits do not increase monotonically with time. The low maximum pit depth for the 350-day set of data may be due to the variation in exposure conditions caused by evaporation and replenishment of test solution over the long test period. At this stage of this work there are only three deepest pits with which to develop a relationship of expected pit depth to time. Such a relationship is expected to follow Equation 1. An example of the power law fit was obtained in part by an iterative calculation of the minimum square of the residuals, and is shown in Figure 2, where $k$ is 3.6 and $n$ is 0.45 . This power law fit will be reanalyzed when pit depth measurements are made after immersions of up to 730 days' length.

\section{CONCLUSIONS}

A type 1 extreme value distribution has been used to analyze deepest pits measured in a large coupon immersion experiment on carbon steel in simulated alkaline radioactive waste. Good correlations with the type 1 distribution are obtained on individual sets of deepest pit data from immersion periods of 64,150 , and 350 days. These distributions have been used to extrapolate the deepest pits measured in the population of corrosion coupons to an expected maximum value on the primary wall of a waste tank. However, the maximum depths measured do not increase monotonically with time. The widely used power law for pit growth was applied to the present limited data set, but adherence to the power law was not demonstrated.

Pitting in carbon steel tanks containing dilute alkaline radioactive waste is prevented at SRS by closely monitored additions of sodium nitrite. The present work indicates that, in simulated wastes containing less than $5 \%$ of the minimum nitrite concentration limit for waste tank operation, the pitting growth rate in carbon steel is low enough to present no risk of penetration of a waste tank wall within one year. Additional data collection should provide the basis to predict better the pitting response of carbon steel to waste with low nitrite levels.

\section{ACKNOWLEDGMENTS}

This paper was prepared in connection with work done under contract No. DE-AC09-89R18035 with the United States Department of Energy. The author gratefully acknowledges the assistance of A. L. Williams in conducting the coupon immersion tests. 


\section{REFERENCES}

1. R. W. Staehle, in Localized Corrosion, National Association of Corrosion Engineers, Houston, 1973, p. i17.

2. H. H. Uhlig, Materials Protection and Performance 12, p. 42 (1973).

3. Advances in Localized Corrosion, National Association of Corrosion Engineers, Houston (1989).

4. M. O. Speidel and P. M. Fourt, in Stress Corrosion Cracking and Hydrogen Embrittlement of Iron Base Alloys, NACE, Houston, 1977, p. 57.

5. J. R. Galvele, "Pitting Corrosion," in Corrosion: Aqueous Processes and Passive Films, Vol. 23, Treatise on Materials Science and Technology, Academic Press, New York (1983).

6. M. B. Ives, in Proceedings of the 12th International Corrosion Congress, NACE International, Houston, 1993, Vol.3B, p. 2096.

7. Z. Szklarska-Smialowska, Pitting Corrosion of Metals, National Association of Corrosion Engineers, Houston, 1986.

8. J.W. Congdon, "Inhibition of Nuclear Waste Solutions Containing Multiple Aggressive Anions," Materials Performance 15, 34 (1988).

9. P. E. Zapp and D. T. Hobbs, "Inhibiting Pitting Corrosion in Carbon Steel Exposed to Dilute Radioactive Waste Slurries," CORROSION/92, Paper No. 98, (Houston, TX: NACE International, 1992).

10 M. Romanoff, Underground Corrosion, National Bureau of Standards, Circular 579, April 1957.

11. R. J. Campana, R. H. Leary, G. H. Reynolds, and H. E. St. John, "Final Report Technical Assistance on 10CFR60 Corrosion and Reliability Monitoring," GA Technologies Document No. GA-C16932, November 1982.

12. Z. Szklarska-Smialowska, D. Grimes, and J. Park, Corrosion Science 27, p. 859 (1987).

13. G. P. Marsh, I. D. Bland, K. J. Taylor, S. Sharland, and P. Tasker, "An Assessment of Carbon Steel Overpacks for Radioactive Waste Disposal," Commission of the European Communities Report EUR 10437 EN, 1986.

14. P. M. Aziz, Corrosion 12, 495t (1956).

15. G. G. Eldredge, Corrosion 13, 51t (1957).

16. H. F. Finley and A. C. Toncre, Materials Protection 3, 29 (1964).

17. M. B. McNeil, "Statistical Issues in Pitting Corrosion of Carbon Steel," in Scientific Basis of Nuclear Waste Management X, Materials Research Society Symposia Proceedings Vol. 84, Materials Research Society Pittsburgh, 1987, p. 199.

18. N. D. Greene and M. G. Fontana, Corrosion $15,25 t$, (1959). 
TABLE 1

COMPOSITION OF SLUDGE SIMULANT

Compound

Sodium Carbonate

Sodium Bicarbonate

Sodium Nitrite

Manganese Dioxide

Aluminum Nitrate

Sodium Oxalate

Sodium Chromate Anhydrous

Sodium Molybdate

Sodium metasilicate

Sodium Phosphate Tribasic

Chromic Chloride

Cupric Nitrate

Ferric Nitrate

Nickel Nitrate

Mercuric Nitrate

Cobalt Nitrate

Sodium Chloride

Sodium Fluoride

Sodium Sulfate

Sodium Nitrate
Concentration (M)

1.73E-02

$4.46 \mathrm{E}-02$

$5.00 \mathrm{E}-03$

$5.75 \mathrm{E}-03$

$1.50 \mathrm{E}-03$

1.94E-04

7.94E-05

1.03E-05

$7.86 \mathrm{E}-05$

$2.23 \mathrm{E}-04$

$3.75 \mathrm{E}-05$

$4.30 \mathrm{E}-05$

$1.25 \mathrm{E}-03$

$1.50 \mathrm{E}-03$

$2.50 \mathrm{E}-04$

3.00E-05

7.14E-04

4.13E-04

$3.63 \mathrm{E}-03$

$4.27 \mathrm{E}-02$ 
TABLE 2

Data from 64-Day Immersion Data from 150-Day Immersion Data from 350-day immersion

\begin{tabular}{|c|c|c|c|c|c|c|}
\hline Rank & Coupon No. & Deepest Pit & Coupon No. & Deepest Pit & Coupon No. & Deepest Pit \\
\hline 1 & 60 & 1.0 & 81 & 1.0 & 33 & 8.7 \\
\hline 2 & 52 & 1.7 & 86 & 7.0 & 47 & 9.5 \\
\hline 3 & 21 & 2.0 & 76 & 11.0 & 23 & 11.3 \\
\hline 4 & 2 & 3.2 & 82 & 11.7 & 25 & 11.5 \\
\hline 5 & 7 & 3.5 & 73 & 12.4 & 46 & 12.4 \\
\hline 6 & 61 & 4.1 & 104 & 12.4 & 70 & 13.7 \\
\hline 7 & 54 & 6.1 & 87 & 13.2 & 59 & 14.4 \\
\hline 8 & 4 & 6.3 & 88 & 13.3 & 48 & 14.8 \\
\hline 9 & 6 & 7.6 & 83 & 13.4 & 29 & 14.8 \\
\hline 10 & 53 & 8.6 & 93 & 13.4 & 28 & 15.0 \\
\hline 11 & 35 & 8.7 & 102 & 14.2 & 30 & 15.6 \\
\hline 12 & 14 & 10.2 & 105 & 16.2 & 49 & 15.6 \\
\hline 13 & 64 & 10.6 & 75 & 17.0 & 42 & 16.3 \\
\hline 14 & 63 & 10.7 & 91 & 17.3 & 24 & 16.9 \\
\hline 15 & 8 & 11.9 & 74 & 17.4 & 44 & 17.0 \\
\hline 16 & 20 & 12.1 & 79 & 18.2 & 58 & 17.2 \\
\hline 17 & 51 & 12.3 & 94 & 18.3 & 1 & 17.4 \\
\hline 18 & 68 & 12.5 & 85 & 18.5 & 11 & 18.3 \\
\hline 19 & 15 & 12.6 & 92 & 18.5 & 41 & 18.5 \\
\hline 20 & 69 & 13.0 & 101 & 18.8 & 57 & 18.9 \\
\hline 21 & 17 & 13.1 & 78 & 19.8 & 50 & 19.2 \\
\hline 22 & 3 & 13.2 & 77 & 20.7 & 39 & 19.5 \\
\hline 23 & 13 & 13.2 & 103 & 21.1 & 43 & 19.8 \\
\hline 24 & 37 & 13.3 & 106 & 21.8 & 31 & 20.1 \\
\hline 25 & 27 & 13.4 & 99 & 21.9 & 56 & 20.4 \\
\hline 26 & 36 & 13.6 & 71 & 22.3 & 45 & 20.6 \\
\hline 27 & 9 & 13.7 & 89 & 22.3 & 52 & 21.9 \\
\hline 28 & 12 & 14.1 & 96 & 22.6 & 55 & 23.0 \\
\hline 29 & 34 & 14.6 & 90 & 22.9 & 40 & 23.2 \\
\hline 30 & 62 & 15.9 & 100 & 23.2 & 18 & 24.5 \\
\hline 31 & 26 & 16.2 & 84 & 23.3 & 19 & 25.3 \\
\hline 32 & 16 & 18.3 & 72 & 25.0 & 10 & 31.4 \\
\hline 33 & 5 & 19.5 & 80 & 25.9 & 22 & 34.3 \\
\hline 34 & 67 & 20.1 & 98 & 26.0 & & \\
\hline 35 & 66 & 22.4 & 97 & 40.8 & & \\
\hline 36 & 65 & 31.3 & 95 & 49.4 & & \\
\hline
\end{tabular}


TABLE 3

RESULTS OF LEAST SQUARES FITS OF

TYPE 1 EXTREME VALUE DISTRIBUTION

Parameter 64-Day Data 150-Day Data 350-Day Data

$\begin{array}{llcc}\text { Slope, } \alpha & 0.18 & 0.13 & 0.20 \\ \text { Intercept, } \mu & -1.56 & -1.92 & -3.15 \\ \mathrm{R}^{2} \text { Coefficient } & 0.94 & 0.88 & 0.88 \\ & & & \\ \text { Expected Deepest } & & & \\ \text { Pit in mils }(\mu \mathrm{m}) & 36(910) & 50(1300) & 30(760)\end{array}$




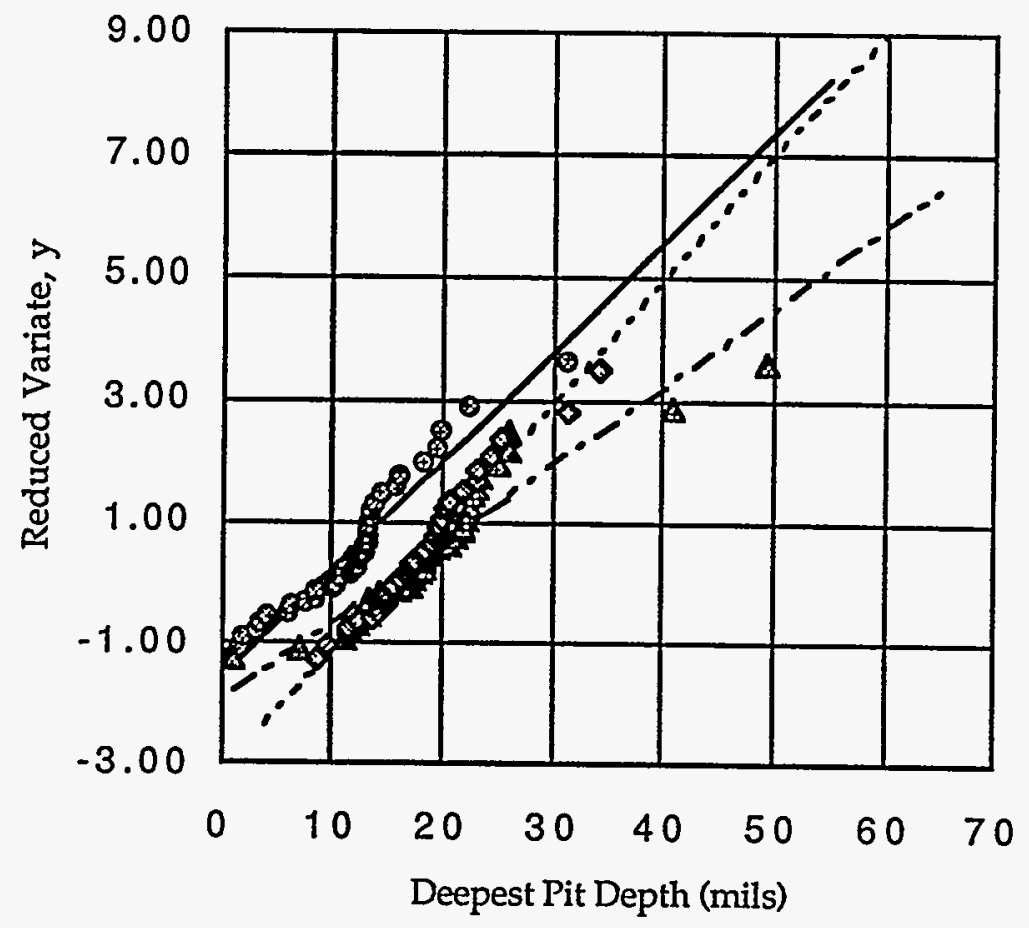

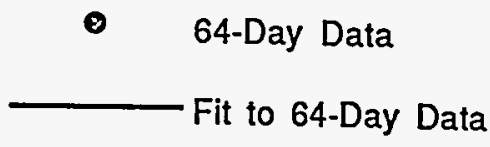

4 150-Day Data

- Fit to 150-Day Data

- 350-Day Data

Fit to 350-Day Data

Figure 1. Type 1 extreme value distribution plot of the deepest pit data. 


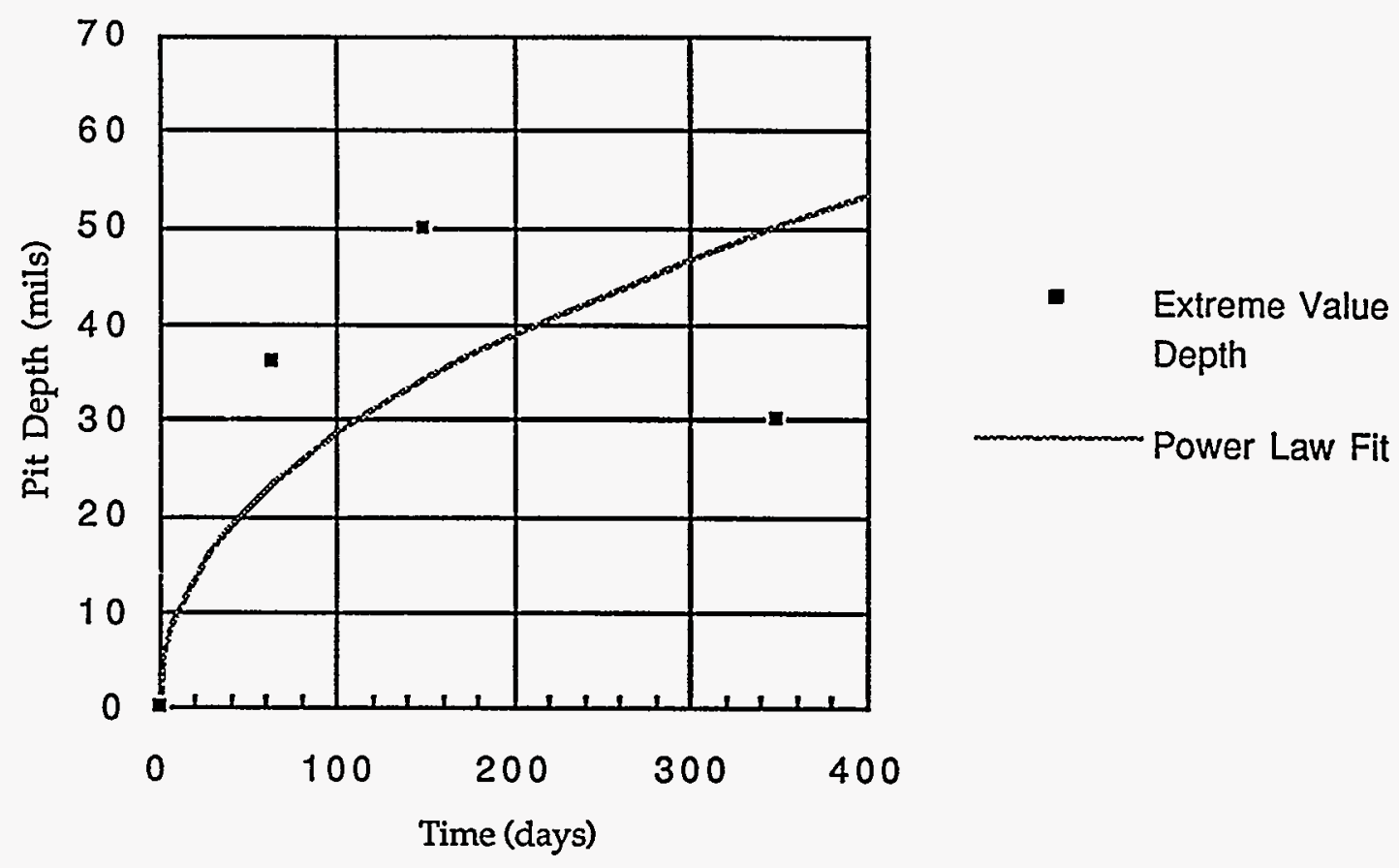

Figure 2. Expected deepest pits and a typical power law fit for carbon steel pitting. 